\title{
La decoración caligráfica árabe y vegetal de las vigas del Museo Diocesano de Barcelona ${ }^{1}$
}

\author{
Arabic calligraphy and vegetal decoration of the beams kept in the Museu \\ Diocesà of Barcelona
}

\author{
Carmen Barceló * \\ Ana Labarta **
}

\begin{abstract}
RESUMEN
Este artículo presenta y comenta la decoración de 13 vigas pintadas que proceden del Palacio Episcopal de Barcelona y se conservan en su Museo Diocesano. Estudia el texto que repite la jaculatoria al-mulk li-llāh en grafía árabe, su significado, el tipo de letra utilizado y el motivo-tipo y busca sus paralelos en diversas construcciones. Describe brevemente los otros elementos decorativos presentes en las vigas: vegetales, de lacería y escudos heráldicos. Su comparación con diferentes edificaciones de la Península Ibérica parece permitir datarlas hacia 1350. Los recortes y mutilaciones que se aprecian en ellas hacen suponer que tuvieron una primera ubicación, hoy ignota, y que en fecha desconocida fueron reutilizadas en la cubierta de la Sala de la Trinitat del Palacio Episcopal, donde aparecieron en 1981 durante las obras de remodelación de la techumbre.
\end{abstract}

Palabras clave: Vigas, cúfico, mudéjar, BarceIona, s. XIV.

\section{CONTEXTO}

El edificio del Palacio Episcopal de Barcelona ocupa un amplio recinto en el centro de la ciudad, en un solar a caballo entre el interior y el exterior de la primitiva muralla romana. Como afirman los arquitectos que lo han estudiado, es un compendio de fragmentos de historia de la ciudad que se remontan al siglo I a. C. y que llegan hasta nuestros días. El complejo edificado ha ido evolucionando a

\begin{abstract}
This article studies a group of 13 painted beams found in the Episcopal Palace and kept today in the Museu Diocesà of Barcelona. The authors read the text in Arabic script, which repeats the expression al mulk li-llāh, comment its meaning, type of script and decoration-unity and search for its parallels in other constructions. They briefly describe the other decorative elements found on the beams: vegetal, plaited, and coats of arms. Comparison with other buildings of the Iberian Peninsula seems to allow dating them to around 1350. The cuts and mutilations seen on them let them assume that they were first located in an unknown place and were reused later on the cover of the Trinitat Hall of the Episcopal Palace, where they were discovered in 1981, during the roof remodeling works.
\end{abstract}

Key words: Beams, Kufic, Mudejar, Barcelona, $14^{\text {th }} \mathrm{C}$.

lo largo del tiempo. Ha disfrutado de ampliaciones que han mejorado su funcionamiento, pero también ha sufrido remodelaciones poco respetuosas con los restos de épocas anteriores. Por ello, el conjunto se muestra como un verdadero microcosmos en el que se pueden identificar, con más o menos fortuna, diferentes episodios de más de veinte siglos de historia de Barcelona (MÀRIA, MINGUELL, 2009-2010: p. 64).

1 El presente artículo es una ampliación del informe que elaboramos a petición del Museo Diocesano de Barcelona [MDB] en 2013. Aprovechamos la ocasión para agradecer la amabilidad de Pere-Jordi Figuerola, encargado de sistemas informáticos y Lumen del Archivo Diocesano de Barcelona, que nos proporcionó fotografías e informaciones.

Catedrática de Estudios Árabes e Islámicos. Universitat de València.

" Catedrática de Estudios Árabes e Islámicos. Universitat de València. 
En el estudio sobre las diferentes etapas constructivas del Palacio Episcopal, los arquitectos Mària y Minguell explican que, durante las reformas realizadas entre 1980 y 1982 se rehízo totalmente la cubierta, muy dañada por las filtraciones de agua, para acondicionar la Sala de la Trinitat como sala de lectura del Archivo Diocesano. La antigua cubierta de esta estancia conservaba vigas decoradas con pinturas con epigrafía árabe y heráldica feudal catalana que hoy se pueden contemplar en el Museu de la Pia Almoina (MÀRIA, MINGUELL, 2009-2010: p. 85).

La Sala de la Trinitat se encuentra en el segundo piso de una nave, perpendicular al cuerpo de la muralla de la ciudad, que consta de planta baja y una galería románica en el primer piso; su construcción data de 12531257. Para poder edificarla, el obispo Arnau de Gurb compró dos casas viejas y las hizo derribar (MÀRIA, MINGUELL, 2009-2010: p. 68).

Según la información que se nos ha facilitado, en el momento en que se desarmó la techumbre las vigas decoradas estaban completamente cubiertas por una espesa capa de hollín. Al no ser evidente que llevaran decoración pintada, no se desmontaron ordenadamente ni se anotó el lugar de la localización de cada una de ellas.

Fue Josep Maria Marí Bonet, director del Archivo Episcopal y actual director del Museo Diocesano de Barcelona [MDB] quien en 1981 descubrió esa decoración, puso en valor las vigas y encargó su restauración, en la que par- ticiparon Beatriz Montobbio y Blanca Montobbio, actual conservadora del Museo (DARNA, 1995: p. 1). Una vez restauradas, se instalaron, sin guardar ningún orden, en el techo de la última planta de la nueva sede del MDB, en la Pia Almoina, para su exposición al público.

Al desarmar la techumbre de la Sala de la Trinitat aparecieron además unas piezas más estrechas y delgadas, con decoración solo en la cara inferior que consiste en una fila de rombos de color rojo sobre fondo amarillo, bordeada por una cinta negra con lunares blancos (Fig. 1). Es grande su parecido con maderas decoradas con filas de rombos que aparecen en otras techumbres, como sucede en la sala baja del palacio del Condestable Miguel Lucas de Iranzo (Jaén) que se considera del siglo XV, aunque ésta es más rica y elaborada (MAÑAS, 1982: pp. 173-178, p. 178).

\section{LAS VIGAS}

Los elementos sometidos a consideración en el presente trabajo son trece vigas que hemos estudiado a partir de un reportaje fotográfico detallado en el que cada una de las piezas venía ya identificada con un número que es el que aquí hemos seguido.

Los maderos tienen una anchura de unos $20 \mathrm{~cm} \times 30 \mathrm{~cm}$ de grosor. Sus longitudes no son iguales; algunas rondan los 6,50 m, mientras que otras miden cerca de 5,50 m; la viga no 13 es mucho más corta y además fue serrada en los extremos con fuerte bisel.

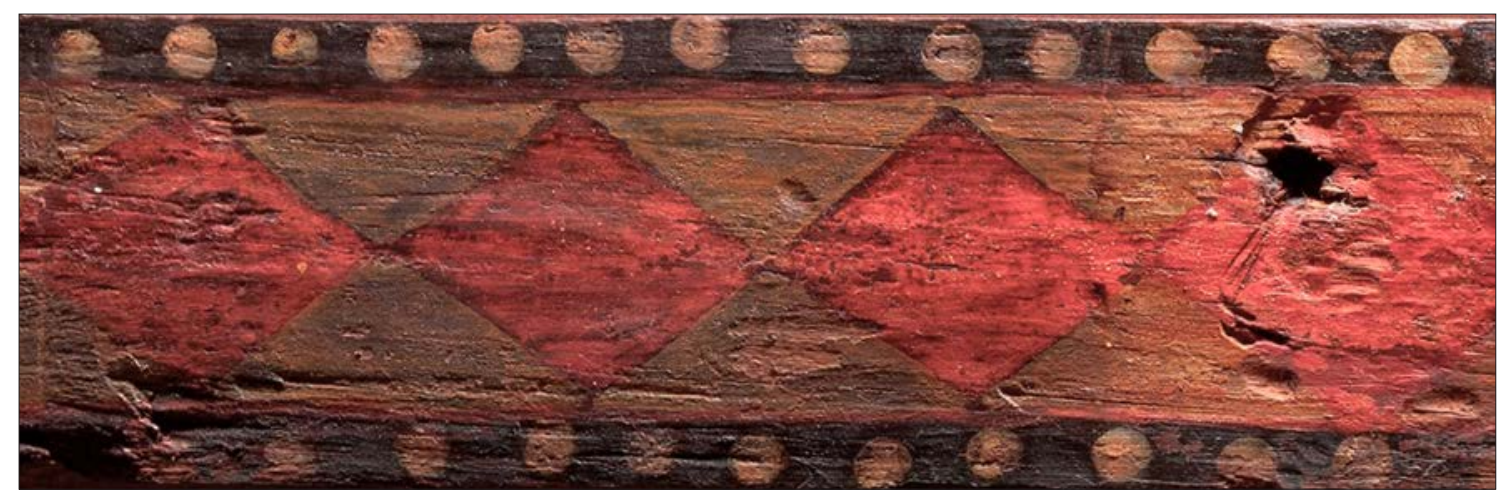

Figura 1. Vigueta. Detalle de los rombos. (Todas las Fotos: Museu Diocesà de Barcelona) 
Las medidas de longitud aproximada ${ }^{2}$ de las trece piezas son:

viga no 1: 6,34 m; viga no 2: 5,40 m; viga no 3 : 6,40 m; viga no 4: 5,60 m; viga no 5: 6,40 m; viga $n^{\circ}$ 6: 5,30 m; viga no 7: 6,20 m; viga no 8: 6,44 m; viga no 9: 5,60 m; viga no 10: 6,54 m; viga no 11 : 6,60 m; viga no $12: 5,46 \mathrm{~m}$; viga no 13: 3,10 m.

Todas ostentan decoración pintada que combina escritura árabe y elementos vegetales en sus dos caras laterales, mientras que la inferior o papo presenta sólo escudos y adornos de lacería y la superior, obviamente, carece de pinturas.

En las páginas que siguen vamos a estudiar la decoración en grafía árabe de las vigas, su significado, tipo de letra y otros detalles de interés, y a describir los elementos vegetales y de lacería; aludiremos sólo brevemente a los motivos heráldicos, que ya han sido objeto de atención (DARNA, 1995).

El repertorio decorativo de las vigas del MDB se inscribe en rectángulos alargados enmarcados por cinta negra con lunares blancos. El interior de estos rectángulos cambia de color, alternando rojo y negro; quedan separados por pequeños recuadros que albergan escudos heráldicos. Igual distribución se aprecia en los papos, donde alternan lacerías y escudos dentro de rectángulos (Fig. 2). Solo dos vigas (nos 9 y 12) ofrecen los enlaces con medios arcos; el escudo queda encerrado en una forma ovalada (no en un cuadrado) y carece del marco trilobulado de hojas presente en el resto (Figs. 3 y 4 ).

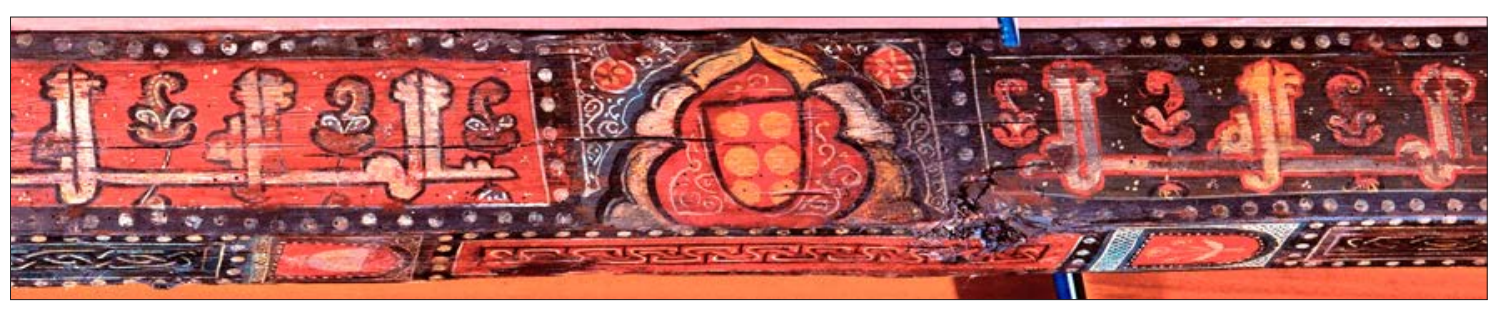

Figura 2. Vista parcial de la viga 6; detalle de uno de los escudos.

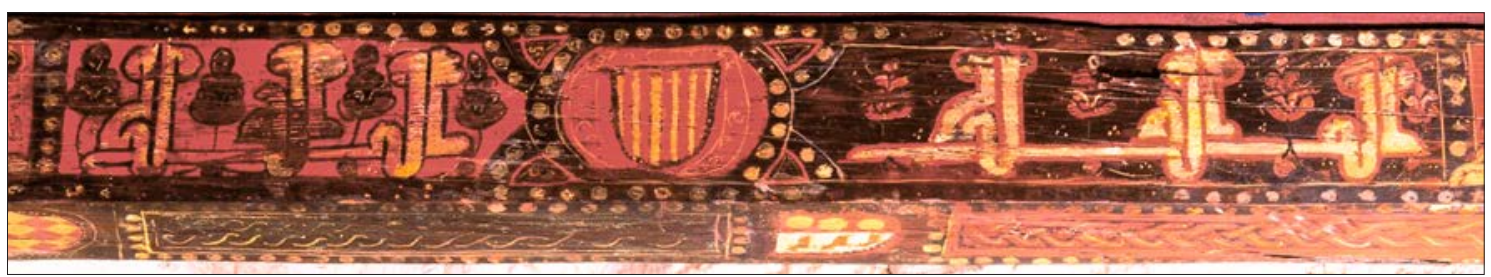

Figura 3. Vista parcial de la viga 9; detalle con motivos epigráficos y escudo.

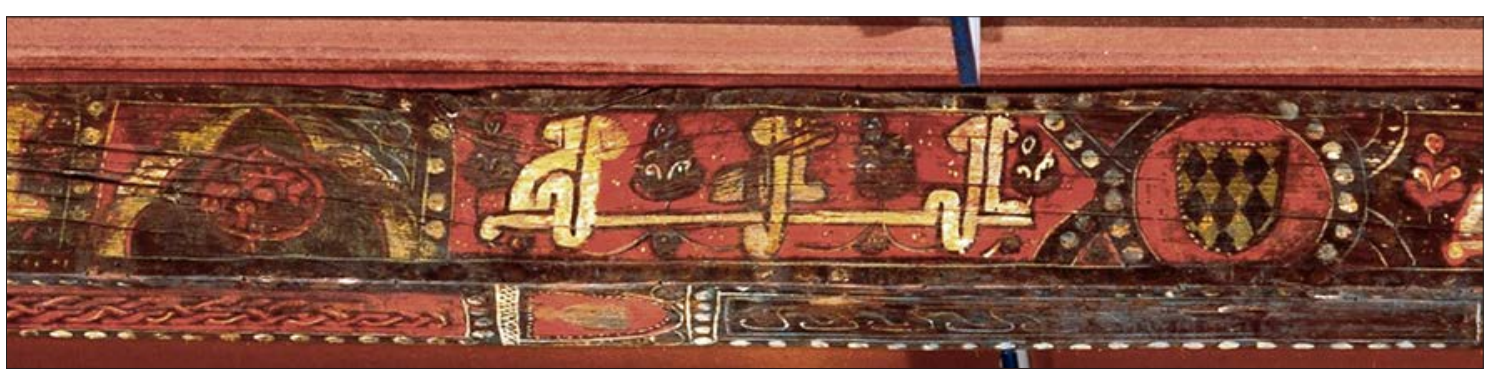

Figura 4. Detalle de la viga 12; motivo epigráfico, escudo y piña.

2 No se nos han proporcionado las medidas exactas, por lo que las longitudes se han calculado a partir de las fotografías y dando al ancho $20 \mathrm{~cm}$. La altura a la que hoy se hallan las vigas hace difícil medirlas. 


\section{LA DECORACIÓN CALIGRÁFICA ÁRABE}

Esta decoración aparece dentro de cartelas rectangulares muy alargadas, bordeadas de cinta de color negro con lunares blancos. Cada uno de los dos laterales de la viga tiene tres de estas cartelas alargadas, que alternan el color del fondo (rojo [r], negro [n], rojo [r]), separadas entre sí por otras cartelas rectangulares más pequeñas en las que figuran motivos vegetales o heráldicos. Son excepción la viga no 9 (dividida en seis cartelas rectangulares) y la viga no 12 (que conserva cinco cartelas, con los colores invertidos en el otro lado).

La escritura árabe es de tipo cúfico, pintada en blanco y/o amarillo, perfilada en otro color: rojo cuando el fondo es negro y negro cuando el fondo es rojo. Ese perfilado de color pudo tener como objetivo dar a la letra el efecto de algo en relieve, recordando así maderas más ricas o yeserías; la decoración floral que se ve entre las letras árabes también parece imitar los adornos típicos de dichos elementos.

Las combinaciones de oro sobre gules y sobre sable que ofrece el letrero caligráfico de nuestras vigas ya se utilizaban en al-Andalus desde por lo menos la época omeya: en el interior de la mezquita cordobesa, en arcos del lateral izquierdo de la sala de oración musulmana, pueden contemplarse inscripciones árabes con las letras de piedra amarilla vista y el fondo pintado de rojo o de azul. Estos juegos de oro y azul o de oro y rojo se mantendrán a lo largo de toda la Edad Media en tierras andalusíes y se conservan todavía yeserías con estas decoraciones procedentes del antiguo alcázar almohade de Murcia (NAVARRO, JIMÉNEZ, 1995: f. 41 p. 82; NAVARRO, 1995: fs. 122-123 p. 189, f. 127 p. 192, f. 134 p. 198) o del palacio de Pinohermoso en Xàtiva (Valencia) (NAVARRO, JIMÉNEZ, 1995: f. 42 p. 83).

El mensaje árabe de las vigas consiste tan sólo en la repetición de la conocidísima jaculatoria de inspiración coránica al-mulk li-llāh, cuyo significado es "el poder es de Dios", "el poder pertenece a Dios", o "Dios es Omnipotente". Es expresión que sigue de cerca a otras que se documentan en muchos lugares del Corán, como por ejemplo XX, 56; $X L, 16$, etc. No ha de sorprender la presencia de expresiones en árabe de contenido islámico en letreros que decoraron iglesias, conventos y palacios cristianos de época medieval: este estilo respondió al gusto de una época por las manufacturas artesanales que producían los andalusíes y otros pueblos norteafricanos u orientales. Nuestros antepasados cristianos gozaron de ellas y no dudaron en incorporarlas a sus edificios hasta que las corrientes italianizantes las desplazaron en beneficio de otros modelos. Recordemos, por ejemplo, que en 1405 Martín I pagaba a "un fuster castellà" y a un musulmán zaragozano, llamado Mahomet, por "els seus treballs en l'enteixinat del Palau Major de Barcelona” (RUBIÓ, 1921, II p. 375, doc. 391); estaba adaptando a sus residencias tres cubiertas de madera, una de ellas de mocárabes (d'almocàrnez) que había hecho traer de Xàtiva (ADROER, 1998).

Por lo que respecta a la voz al-mulk, se usó en todas las manifestaciones artísticas (cerámica, metal, madera, yeserías, mármol...) y se documenta sin interrupción desde el siglo IX -como mínimo- tanto en Oriente como en el Occidente islámico, incluida la Península Ibérica. No se han estudiado en detalle las periodizaciones de sus variantes al-mulk li-llāh, al-mulk li-llāh wahda-hu y al-mulk al-dā'im li-llāh. Por ello la presencia de la frase al-mulk li-lläh no nos sirve para determinar la cronología de las piezas, en oposición a otras expresiones religiosas que sí orientarían sobre su datación, como por ejemplo: "loado sea Dios" (al-hamdu li-llāh), cuyo uso comienza con la expansión del imperio almohade; o "Dios es el único vencedor" (wa-lā gālib illā - lläh), conocido lema de la dinastía nazarí del reino de Granada.

La frase presente en nuestras vigas, que se repite de derecha a izquierda varias veces en cada una de ellas siguiendo el sentido normal de la escritura árabe, en muy pocos casos está con su grafía correcta, ya que en la mayor parte de las ocasiones ha sido objeto de la intervención de restauradores que desconocían este alfabeto y no se percataron de que el diseño se repetía. Al contemplarlas, 
puede observarse que ha habido distintas manos que han retocado el texto, tal vez en épocas diferentes; unas han sido más tímidas y respetuosas, otras más alegres y atrevidas; alguna ha desfigurado completamente el ductus árabe original. Un análisis de los pigmentos presentes en cada zona podría ayudar a detectar las fechas y los responsables de las diferentes actuaciones.

En nuestra descripción nos basamos en aquellas vigas o fragmentos de ellas que resultan a nuestro entender más acordes con el modelo original. Prescindiremos por completo de aquellas que presentan hoy unos trazos ininteligibles. Antes conviene hacerse una idea de cuál era el diseño que sirvió de modelo. Para ello hemos reconstruido cuál pudo ser el aspecto original del escrito (Fig. 5).

El tipo caligráfico cúfico, uno de los más antiguos en el ámbito árabe, se caracteriza por sus formas geométricas, rigidez de algunos trazos y la ausencia de los puntos diacríticos y demás signos gráficos complementarios presentes en la escritura cursiva (OCAÑA, 1970). Fue evolucionando al amparo de diferentes gobiernos, que institucionalizaron determinadas variantes de este estilo. Sus características permiten determinar la etapa histórica en que tales signos fueron utilizados. De ahí que se hable de cúfico omeya, abbasí, fatimí, almorávide, selyuquí, mameluco, almohade, nazarí, etc.

La letra que se observa en estas pinturas es la utilizada en un largo período que comienza en el siglo XIII bajo el gobierno almohade y se perpetúa, con ligerísimas variantes, en el reino nazarí de Granada hasta el siglo XV, compartiendo vigencia con el denominado "arte mudéjar" en los territorios cristianos de las coronas de Aragón y Castilla.

Entre las peculiaridades que pueden señalarse en el trazado de las letras de nuestras pinturas están:

- La letra mim. No tiene la figura redondeada característica sino que es algo apuntada y además no se ha escrito en el centro de la línea sino por encima.

- La letra kāf. Su asta se curva, adaptándose a la forma -también curva- que se le ha dado al cuerpo principal de la letra que, además, acaba con un remate hacia abajo.

- La letra hā'. Debido a la intervención de los varios restauradores, no hay un modelo único que permita establecer paralelos aunque todas muestran el cuerpo apuntado en la base. Su remate, cuando lo tiene, no adquiere un desarrollo vertical, sino que es muy corto, a veces inclinado hacia la izquierda.

Aunque presentes ya en determinados productos del cúfico almohade, todos estos elementos son habituales en el cúfico nazarí que podemos ver en la Alhambra y en manifestaciones mudéjares de los siglos XIV y XV.

En buena parte de las vigas sorprende que la primera letra de la derecha (alif) no tenga su base en la línea de escritura sino que descanse sobre un espolón hacia atrás que sale de la letra lām para sustentarla; lo esperable sería que no ofreciera ese vástago a la derecha y que la base del alif reposara sobre la línea de

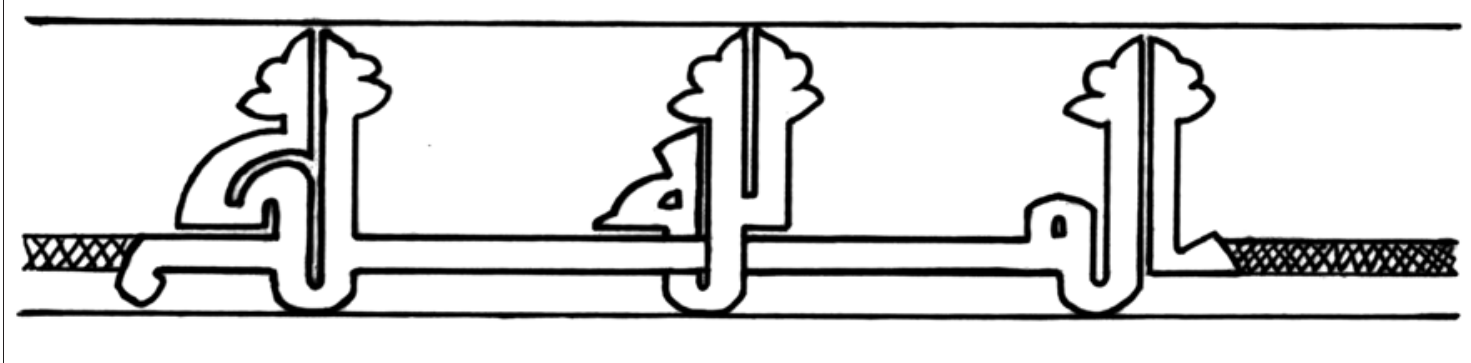

Figura 5. Reconstrucción del motivo-tipo árabe al-mulk li-llāh presente en las vigas. 
escritura. En ocasiones la base de ese signo presenta un apéndice hacia abajo simétrico al de kāffinal, que aquí falta.

Es difícil hoy poder determinar con certeza absoluta cómo era el primitivo remate de las tres parejas de astas que suben hasta la cenefa superior ¿Eran lobuladas o no? Tras las distintas intervenciones de restauradores en la decoración pintada de las vigas no es posible determinarlo con seguridad. El detalle no es indiferente, pues el tipo que adopte ese remate indicaría una época u otra. Otro rasgo que ayuda a fijar una datación es que las astas suban paralelas o que acaben separándose en ángulo.

En las vigas se distinguen tres modelos de astas que:

a) suben paralelas y los remates foliados se separan formando ángulo obtuso (Figs. 6y 7);

b) suben paralelas y acaban con remate foliado a derecha e izquierda (Fig. 8);

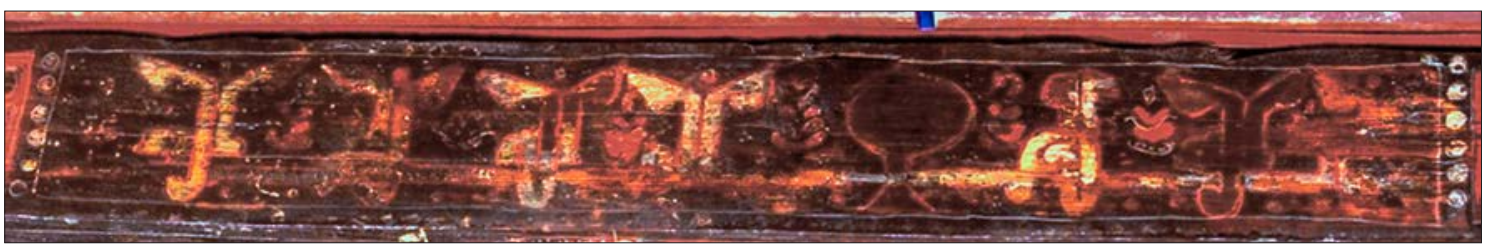

Figura 6. Viga 11. Detalle de los remates foliados formando ángulo obtuso.

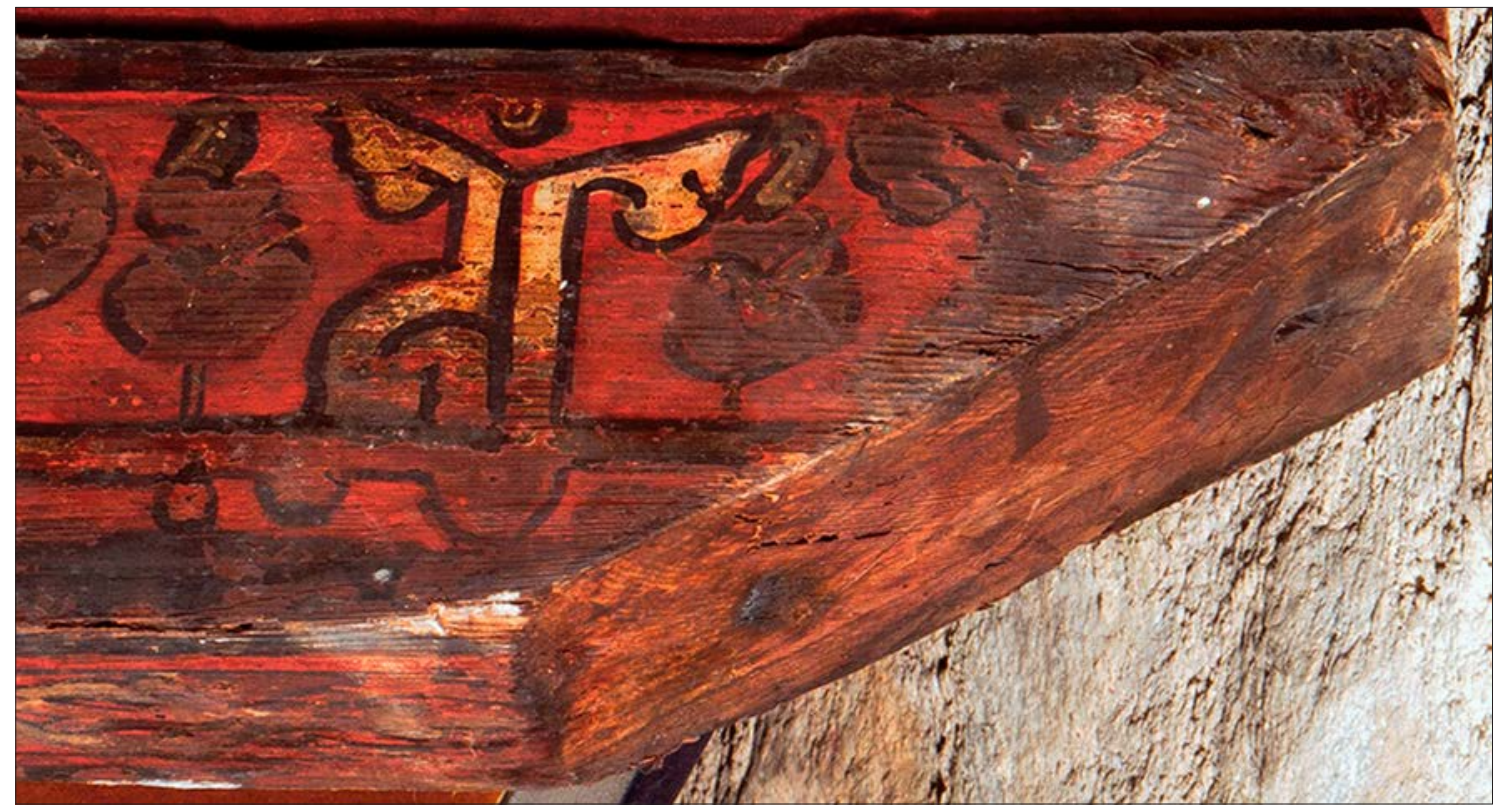

Figura 7. Viga 13. Detalle de los remates foliados formando ángulo obtuso.

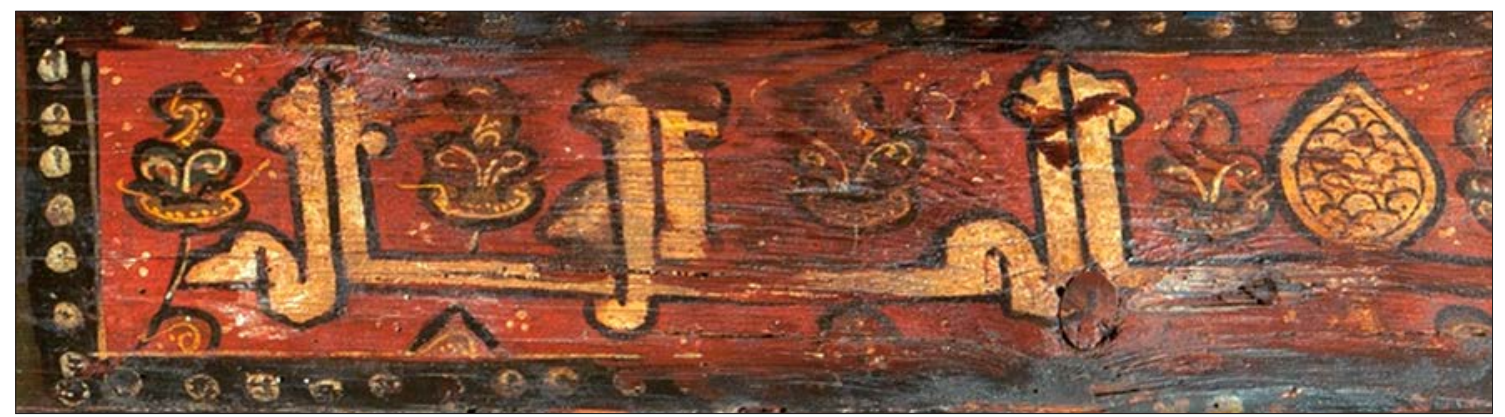

Figura 8. Viga 3. Detalle de los remates foliados verticales. 


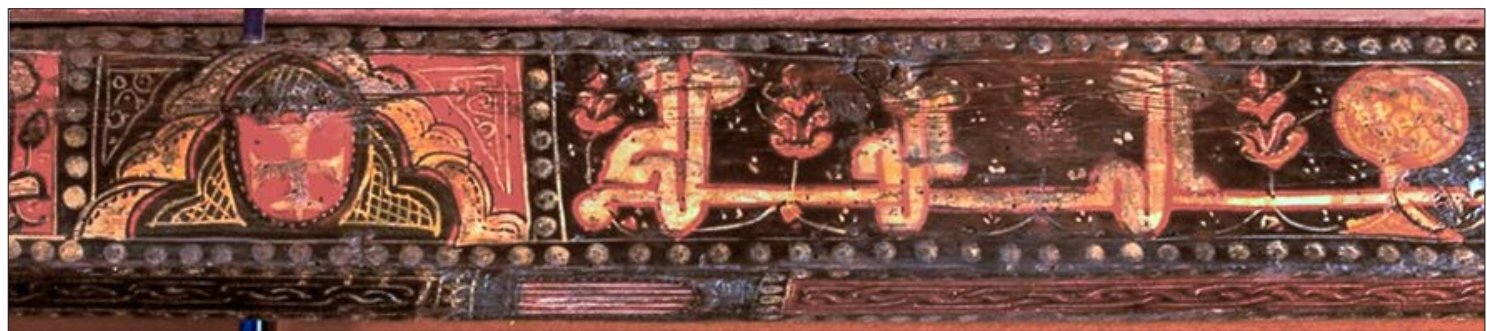

Figura 9. Viga 12. Detalle de los remates con un lóbulo a cada lado.

c) suben paralelas y acaban con remate de un lóbulo a cada lado (Fig. 9).

En cuanto al modelo a), se puede ver un diseño similar de la misma expresión en las cartelas de la chapa de bronce que cubre la puerta del Perdón de la catedral de Sevilla, obra almohade del primer tercio del siglo XIII (SALEM, 1978), aunque en ellas las astas paralelas se entrelazan.

Cabe recordar que el cronista Pere Antoni Beuter da testimonio de que en 1537 la puerta de la Trinidad de la ciudad de Valencia aún conservaba la chapa metálica antigua, decorada con lletres morisques esculpides, en la que constaba que había sido realizada en 1227 (BEUTER, 1538: lib. 1 cap. 19). El viajero Antonio de Bruselas estuvo en la ciudad en 1563, las vio y dibujó el texto árabe que las fecha (KAGAN, 1986: 192). Cualquier persona que visitara la ciudad de Valencia o viviera en ella desde su conquista por Jaime I, pudo verlas e incluso inspirarse en sus motivos y letreros para reproducirlos en otro lugar. Así, remates formando ángulo obtuso como los mencionados se pueden observar en las bandas con caligrafía que enmarcan en su parte superior los frescos medievales que conmemoran la conquista de Mallorca por Jaime I, descubiertos en 1961 en el Palau de Caldes (luego Berenguer d'Aguilar), en la calle Montcada de Barcelona y ahora conservados en el Museu Nacional d'Art de Catalunya (MNAC, No. Inv. 071447-CJT). También se ven en los al-mulk de las vigas descubiertas en la calle Lledó, 15 de Barcelona (MASPOCH 2013: f. 6 y foto en color p. 271; por una errata se remite a Lledó, 7).

Otro ejemplo de al-mulk li-llāh con astas formando ángulo está pintado en la madera que corre bajo la techumbre del Palacio de los Córdoba, actual Convento de las Teresas, en Écija (Sevilla), considerado de los siglos XIV y XV (PAVÓN, 1976: Im. 182).

Para encontrar paralelos o diseños próximos a los tipos b) y c) antes descritos hay que acudir al amplio muestrario de la Alhambra de Granada; otros se ven en el Alcázar del rey don Pedro (Sevilla) y en restos monumentales del período mudéjar en el reino de Castilla. Observaremos así que en las yeserías de la capilla de San Bartolomé de Córdoba (finales del siglo XIV o primera mitad del XV) las astas suben y terminan paralelas, con remates foliados y la letra mim se escribe, algo apuntada, sobre la línea. No hemos logrado encontrar el motivo al-mulk li-llāh con grafía similar en las manifestaciones mudéjares aragonesas.

Astas paralelas foliadas del tipo b) aparecen también en los al-mulk li-llāh grabados en relieve en las tabicas recuperadas del techo de la nave mayor de la iglesia segoviana de San Millán. Aunque esta iglesia fue construida en el siglo XII, sufrió diversas intervenciones en la techumbre, sustituida finalmente por una de ladrillo en 1669 (TORRES BALBÁS, 1949: f. 400, p. 353 y p. 355; HERRERA, CABAÑERO, 1999: 239 f. 15).

Ofrecen otro ejemplo de astas paralelas, rematadas en un lóbulo del tipo c) las yeserías que decoran el Alcázar de Sevilla edificado por Pedro IV a mediados del siglo XIV (TORRES BALBÁS, 1949: p. 371 f. 426). En el Salón del Trono o de los Embajadores de este alcázar se adornó la estancia combinando epigrafía árabe, decoración floral, representaciones figurativas y las armas de la realeza de León y Castilla. 


\section{EL MOTIVO-TIPO AL-MULK LI-LLĀH}

Como se puede ver en nuestra reconstrucción de la frase árabe, la base de la escritura se encuentra en la traza de la palabra al-mulk; sus letras I $k$ finales se han separado alargando el nexo horizontal, y en medio se ha incluido y enlazado li-llāh.

El maestro de la epigrafía andalusí Manuel Ocaña denominó "motivo-tipo" a este modo de caligrafiar jaculatorias que se empieza a producir en el occidente islámico a partir de época almohade. Por tratarse de concisas frases encomiásticas consagradas a Dios y estar compuestas en caracteres cúficos, el motivotipo consiente incrustar una palabra dentro de otra, como se observa en los diseños del motivo al-hamdu li-llăh (loado sea Dios) realizados por el propio Ocaña. Como dejó escrito: "todo motivo-tipo es el producto de potenciar el valor estético de cuantos signos cúficos intervienen en el mismo y enlazarlos con sus respectivos nexos de unión, de suerte que el conjunto adquiera un rango ornamental y artístico indiscutibles" (OCAÑA, 1990: p. 94).

En los yesos de la Alhambra se encuentran muchos y variados ejemplos de estos motivos, entre ellos la jaculatoria presente en nuestras vigas aunque, al tratarse de una residencia real y desarrollarse en los muros del palacio, las astas de las letras se alargan y entrecruzan, formando arquillos y complejos entramados de carácter arquitectónico (PUERTA, 2015: 108 f. 16). Señalaremos, sin ánimo de exhaustividad, que pueden observarse en el palacio de Comares, la Sala de las Camas, Mirador de Lindaraja, Oratorio del Partal, Torre de la Cautiva, Torre de las Infantas y en el Generalife (PUERTA, 2010: pp. 95, 115, 140, 232, 269, 275, 301, 303, 306, 321, 322, 346).

Hemos hecho un dibujo esquemático del motivo-tipo al-mulk li-llāh tal como se presenta en la parte alta de la galería Sur del patio de los Arrayanes y en el Serrallo del palacio de Comares, ambos en la Alhambra, (a partir de Corpus epigráfico, 2007; loc. 0102381107 y 0102381108) (Fig. 10). Se observará que en este ejemplo el enlazado de las palabras li-llāh con la línea base de la escritura es más elaborado que el de nuestras maderas, pues el nexo de unión de ambos lām pasa por debajo. Diseños más sencillos y similares al que reproducen las vigas se muestran en otros puntos de la Alhambra. Se repiten dentro de arcos simulados formados por hojas que imitan un tejido cubriendo las paredes. En algún caso, es el nexo del primer lām el que pasa por debajo de la línea, como puede verse en la decoración del oratorio del Partal (PUERTA, 2010: p. 275). En otras ocasiones, lo hace el del segundo, al igual que en nuestras vigas, por ejemplo en las yeserías que adornan las paredes del oratorio de la madraza Yūsufiyya de Granada (1349). Un al-mulk li-llāh de dicha madraza, diseñado entre hojas, tiene un trazo muy parecido al de las vigas catalanas (ANGULO, 1984: I, p. 511, f. 744).

\section{LOS MOTIVOS VEGETALES}

En palabras de Manuel Ocaña, el motivotipo de época almohade presentaba "adita-

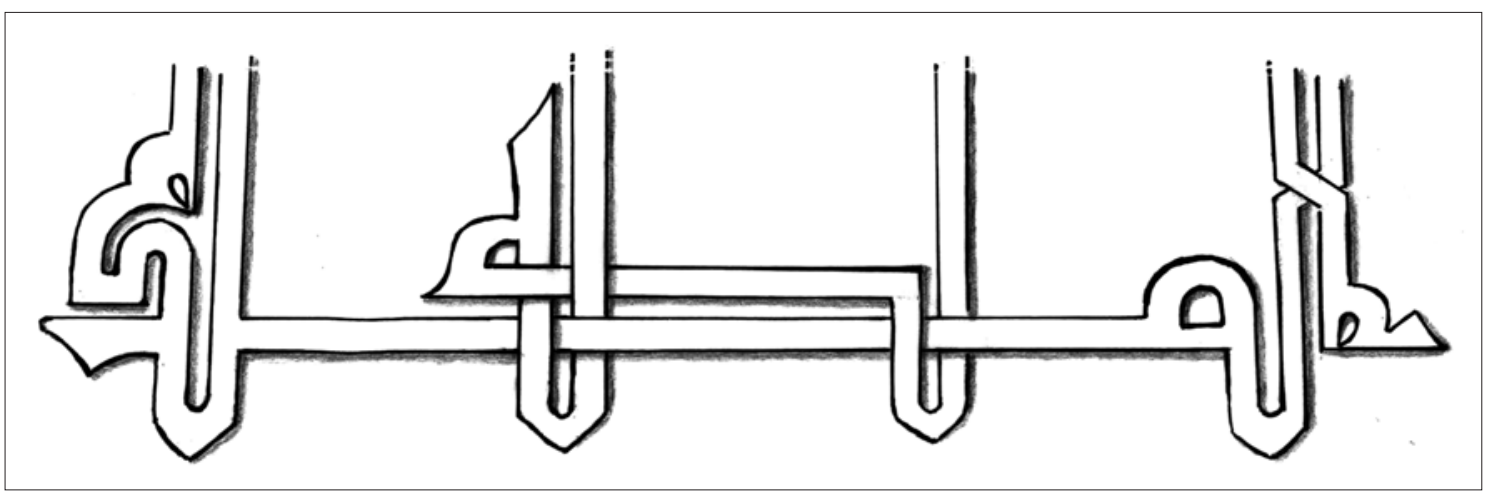

Figura 10. Dibujo del motivo al-mulk li-llāh presente en las yeserías de la Alhambra. 
mentos florales con los que, por lo común, se rellenaban los vacíos dejados en la composición" (OCAÑA, 1990: p. 95). El repertorio vegetal que aparece entre las letras árabes de las maderas de Barcelona es escaso e incluye los tipos:

a) flor de loto / espiga

b) árbol

c) hoja / palma

d) piña.

\section{a) Flor de loto / espiga}

El modelo más repetido es el que Pavón denomina "flor de loto" (PAVÓN, 1981: p. 51), pero evolucionado. En este caso los vegetales asemejan una especie de espigas de diversa factura; unas tienen tres niveles de bifolios y una hoja central

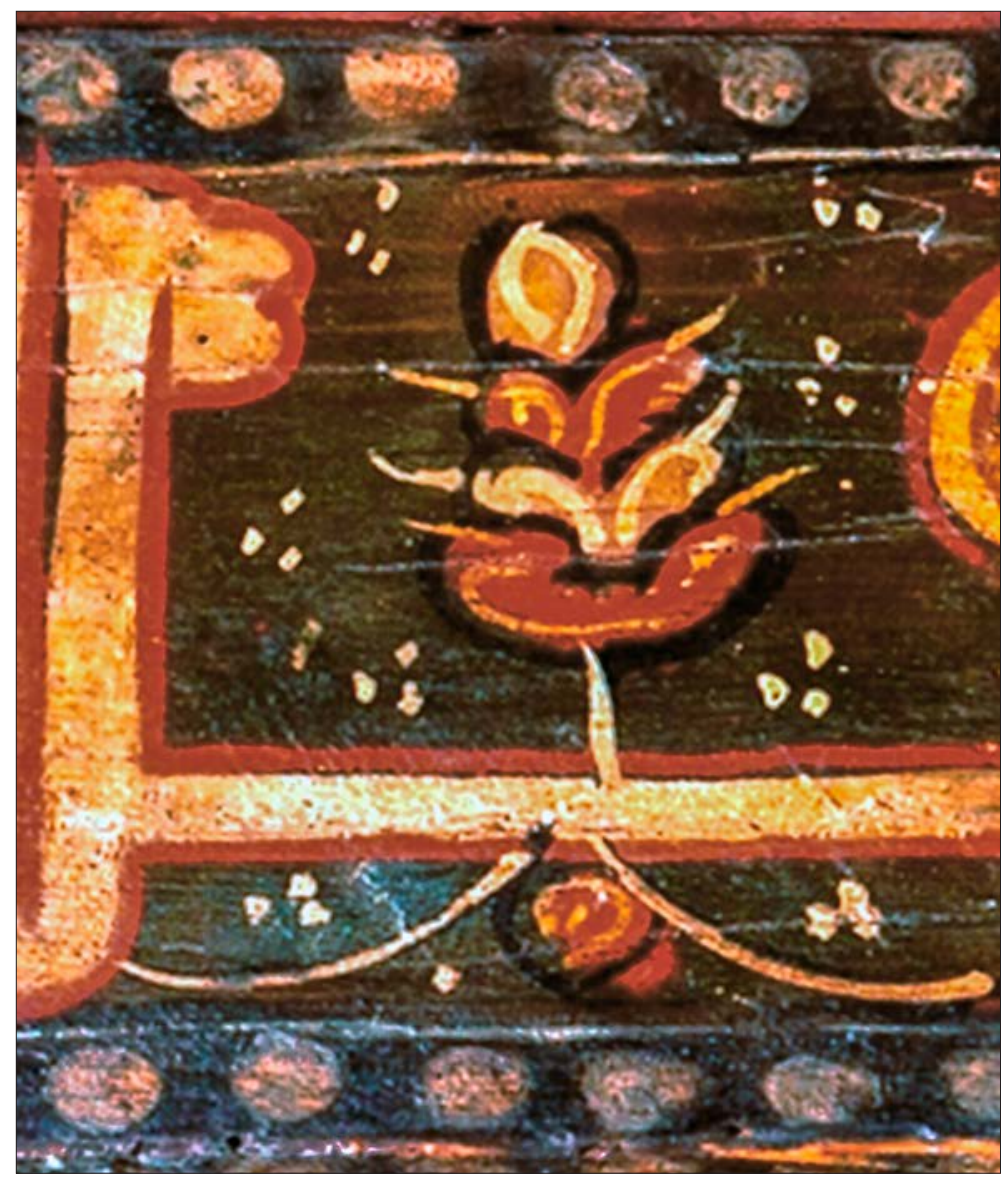

Figura 11. Ejemplo del motivo vegetal de espiga. arriba; otras, sólo dos niveles (Fig. 11).

Estas espiguillas tienen un pequeño tallo; las bases de los tallos van unidas mediante unas líneas curvas, que recuerdan la cenefa en cadenetas, forma antiquísima que se ve con frecuencia en la Alhambra y lo mudéjar (PAVÓN, 1981: Tabla XI p. 79). En nuestro caso esas líneas curvas parecen imitar la decoración floral de la primera mitad del siglo XIII que acompañaba el fondo de la escritura y se desarrollaba formando círculos, de los que salían palmetas digitadas, pimientos y otros elementos vegetales, rellenando así los espacios vacíos al mismo tiempo que decoraban.

Quisiéramos hacer notar que la forma y la colocación entre letras del motivo descrito son muy parecidas a las del friso superior de los frescos del Palau Caldes de la calle Montcada.

\section{b) Árbol}

El otro tipo vegetal usado es un árbol que evoca el árbol de la vida o hom (PAVÓN, 1981: Tabla XXVI p. 147), como llaman a veces a este tipo de adorno. Cuando la cartela repite dos veces el motivo al-mulk li-lläh, la línea de escritura los une y este árbol hace de separador entre ellos; unas veces su tronco está detrás de la línea y otras veces delante. Su copa se compone de un doble círculo en el que se inscriben una especie de brácteas, con un punto, que simulan las hojas (Fig. 12).

Recuerda el "árbol de la vida con piñas fantaseadas" que se ve en muchos platos, cuencos y escudillas de cerámica de Paterna del siglo XIV (GONZÁLEZ MARTí, 1944: fs. 163, 164, 165, Im. V; MARTÍNEZ CAVIRÓ, 1991: f. 124) y alguna de reflejo metálico de Málaga del siglo XV (MARTíNEZ CAVIRÓ, 1991: fs. 62-64, pp. 82-83). 


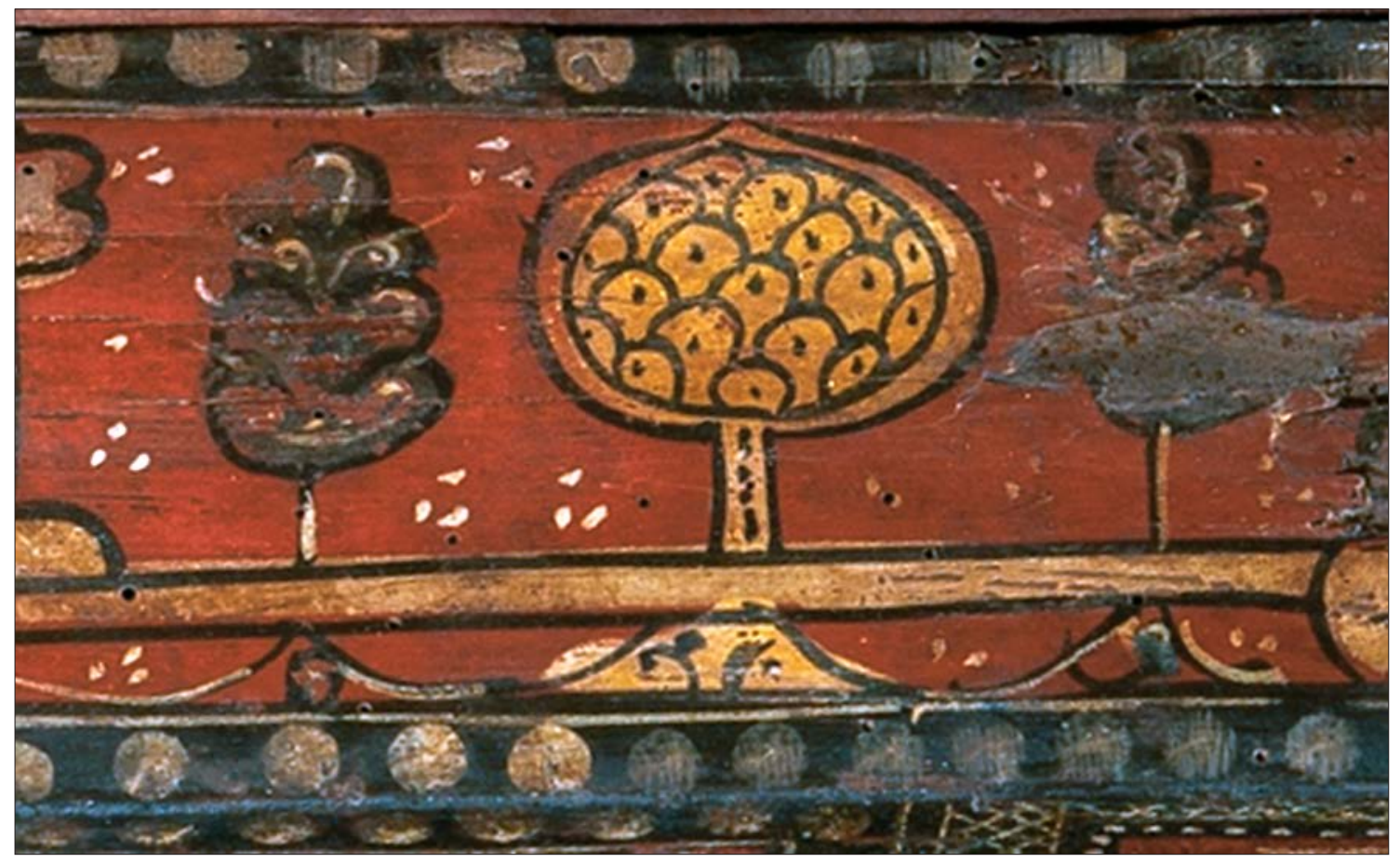

Figura 12. Ejemplo del motivo "árbol de la vida".

\section{c) Hoja o palma}

Las cartelas con la jaculatoria al-mulk li-llāh están separadas unas de otras por unos rectángulos en los que se inscribe un esquema triangular isósceles, con el vértice en la parte central superior, cerrado por seis hojas dobles denticuladas, entrecruzadas y dispuestas en forma simétrica con respecto al eje central de un arco lobulado simulado (Fig. 13).

Como afirmaba Angulo hablando de la Alhambra, "los decoradores granadinos sustituyen con frecuencia los arcos por hojas"

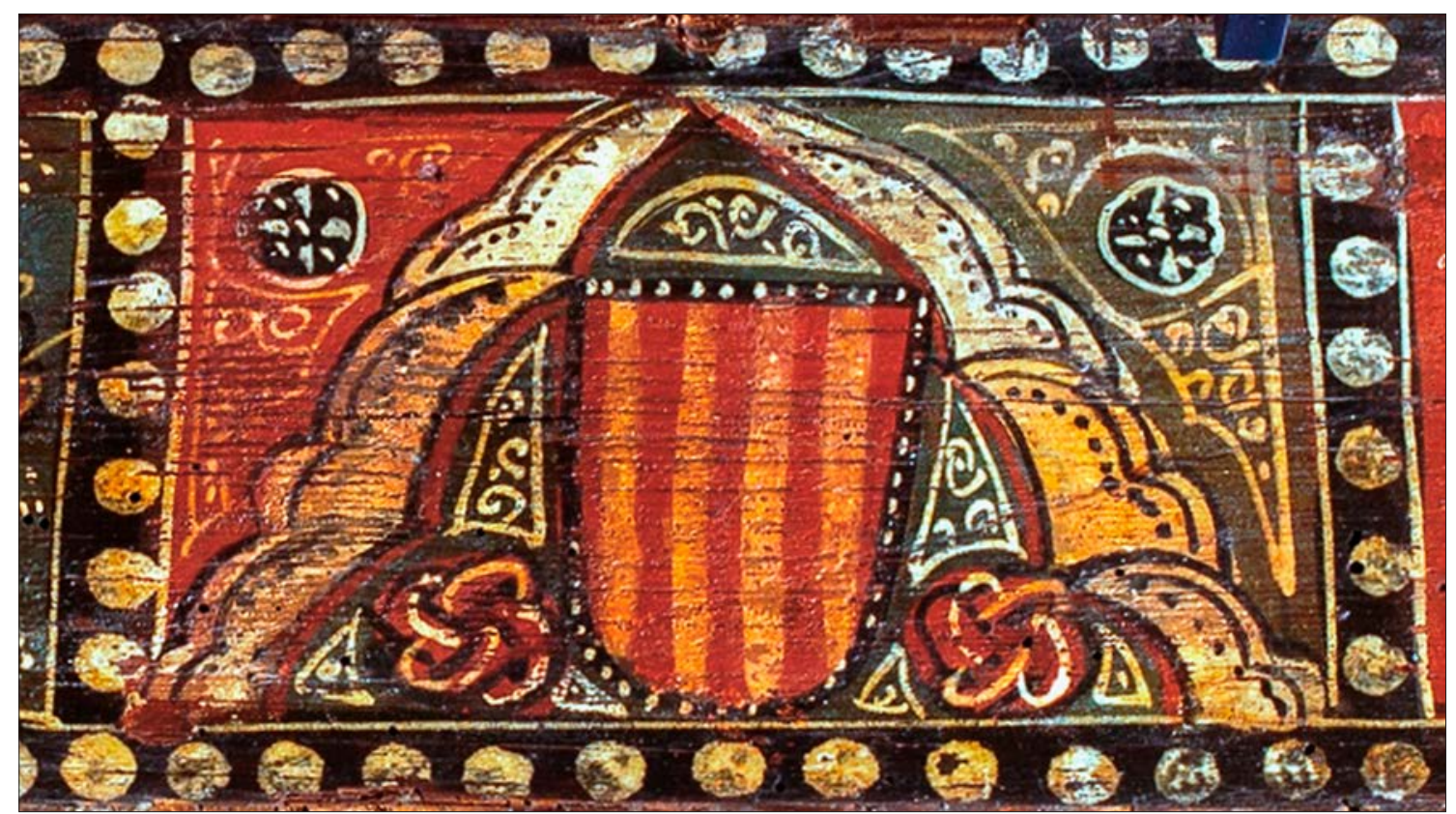

Figura 13. Detalle de un arco polilobulado. 
(ANGULO, 1984: vol. I, p. 510.). La que nos ocupa es del tipo que los historiadores del arte almohade conocen con el nombre genérico y convencional de "palmas" (TORRES BALBÁS, 1949: p. 50), aunque su forma no supone la derivación directa de la hoja de palmera.

Todos estos bifolios, perfilados por dentro con una hilera de puntos y una línea continua que refuerza su dibujo externo, se parecen mucho a las hojas perforadas que presentan yesos, fechados en el siglo XIV, de la Alhambra y del mudéjar castellano de Sevilla y Toledo. En Granada se ven en el Partal (1302-1309), el palacio de los Leones (1380), la Sala de Abencerrajes, Mirador de Abencerrajes, Sala de los Ajimeces, Mirador de Lindaraja y Sala de Dos Hermanas (PUERTA, 2010: pp. 175, 185, 225, 232, 237, 270). Están en yesos del Alcázar de Sevilla (PAVÓN, 1981: Tabla XX-55, foto 397). Aparecen también en los yesos de Santa Clara la Real de Murcia (hoy Museo Arqueológico Provincial) (NAVARRO, 1995: fs. 122 a 124, 128, 129, pp. 189-190, 193-194) y en la Casa de Onda (NAVARRO, JIMÉNEZ, 1995b: fs. 151, 152, 157, pp. 215-216, 219).

Estos arquillos, formados igualmente por tres hojas dobles, aunque lisas, se ven por primera vez en estelas funerarias pre-almohades del Levante peninsular, como la lauda sepulcral de Ibn al-Azraq al-Fihrī, sepultado en Murcia en 1171, inscripción que se conserva en el Museo Arquológico de Murcia (LÓPEZ GUZMÁN, 1995: p. 130, f. 24).

\section{d) Piña}

En el interior de los arquillos se sitúan casi siempre escudos heráldicos. Sólo en dos vigas se ve un nuevo motivo vegetal: un fruto estilizado que pudiera ser piña, granada o bien una alcachofa (véase aquí Fig. 3) (PAVÓN, 1981: Tab. VI y VII, pp. 45-49).

\section{LOS PAPOS DE LAS VIGAS}

El papo o cara inferior de las vigas no presenta epigrafía árabe ni motivos vegetales. Para decorar esa zona se usaron algunos entramados de lacería y diversos escudos heráldicos encerrados en rectángulos.

El trazado de las cubiertas de madera de tradición árabe se basa en una serie de polígonos en resalte que se entrecruzan, simulando estrellas, en esquemas compositivos repetitivos. En los espacios libres entre dichos polígonos se pintan cenefas florales. Se ven figuras similares en los frescos de lacería conservados en zócalos interiores de viviendas y palacios andalusíes y en el despiece simulado de paredes en el exterior de castillos. Son elementos muy elaborados y complejos, que siguen ritmos geométricos. Nada tiene que ver esa geometría con lo que se ve en las vigas del MDB.

En los territorios árabes medievales convivieron con esta decoración geométrica motivos de lacería de tradición clásica, que se hallan en nuestra Península en mármoles y marfiles desde época califal o antes y se siguieron utilizando por los iluminadores en las artes del libro hasta principios del siglo XVII. Su desarrollo presenta esquemas simples muy alejados de los varios modelos antes señalados.

En las vigas que nos ocupan, la lacería se basa en cruzados sencillos, con trenzados de ocho dobles, enlazados entre sí de varias maneras. En general, son más fáciles de distinguir los que se hicieron sobre fondo rojo, destacando el lazo mediante líneas en blanco y negro. Por contra, las que se trazaron sobre fondo negro apenas son visibles en la actualidad o han sido intervenidas de forma poco afortunada.

Ofrecemos un pequeño resumen de los diferentes modelos junto con algunos paralelos, a título ilustrativo, sin que ello implique en absoluto una correlación cronológica entre ellos, sino, por el contrario, su secular perduración.

El modelo más repetido es el que se observa en las vigas nos 1, 2, 3, 4, 6 y 8 (Fig. 14), que recuerda las cenefas del cuello del vaso nazarí de Palermo (siglo XIV) (MARTínEZ CAVIRÓ, 1991: f. 78 p. 90). 


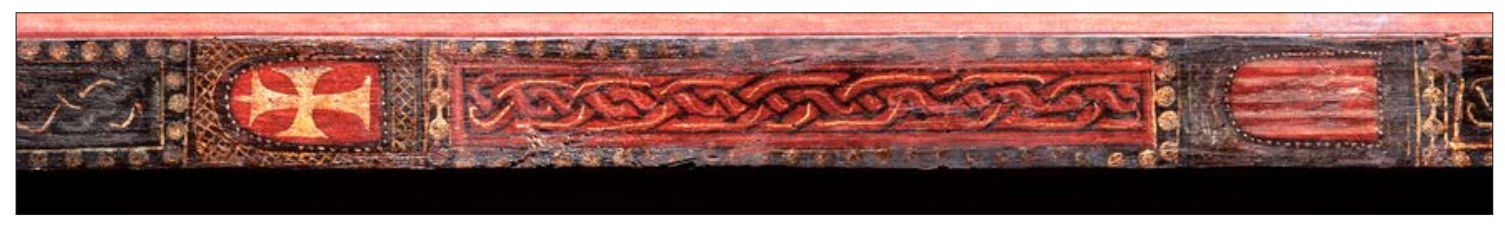

Figura 14. Detalle de la lacería presente en las vigas 1, 2, 3, 4, 6, 8.

Otro modelo de los más repetidos en las vigas es el de ochos dobles (vigas 1, 8 y 12) (Fig. 15) que podía verse ya en los mármoles del año 960 dC. que decoraban los baños de Medina Azahara (Córdoba) (VALLEJO, 2010, Ims. 197 p. 250, 355 p. 429 y 368 p. 445.), a los que pertenecía también el arquito conservado en el Museu Diocesà de Tarragona; y se ve, labrado en marfil, en la arqueta de Leire (Pamplona, fechada en 1005). Este esquema pervive en las decoraciones librescas de época mudéjar, decorando sobre todo Coranes, como dos procedentes del hallazgo de Almonacid de la Sierra (Zaragoza) conservados en la Biblioteca Tomás Navarro Tomás (CCHS-CSIC, Madrid). El primero, (ms Junta no XVI) puede datarse por el papel entre los años 1522 y 1559; el segundo (ms Junta n XLVII) se puede fechar entre 1532 y 1568 (MATEOS, 2010: ficha 11 pp. 146-149).

En otros casos la lacería se acerca más a modelos clásicos greco-latinos (vigas nos 2, 5 y 12) (Fig. 16).

También se muestran labores de cestería más complejas (viga no 8) (Fig. 17) que recuerdan los lazos que se observan en el vaso nazarí del siglo XIV de Palermo (MARTíNEZ CAVIRÓ, 1991: f. 78, p. 90). Lacerías similares perviven en la decoración libraria, como la de una obra de gramática árabe copiada en época morisca, guardada ahora en la Biblioteca Tomás Navarro Tomás (CCHS-CSIC, Madrid, ms Junta nº LIX, de los siglos XV-XVI) (MATEOS, 2010: ficha 4 pp. 133-135).

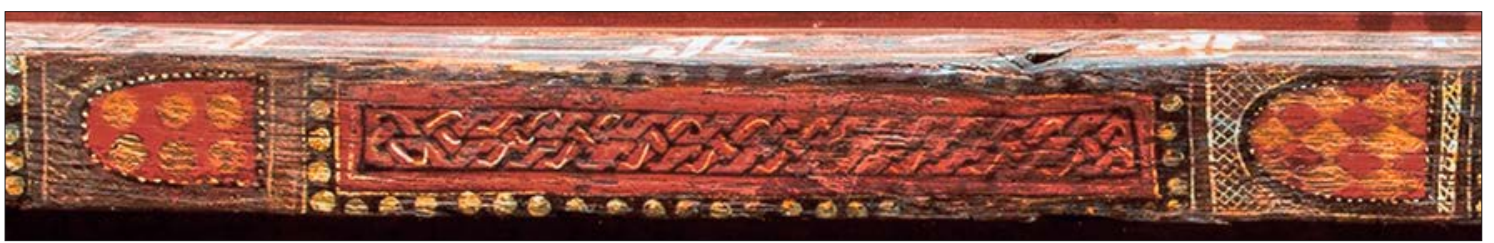

Figura 15. Detalle de la lacería presente en las vigas 1, 8 y12.

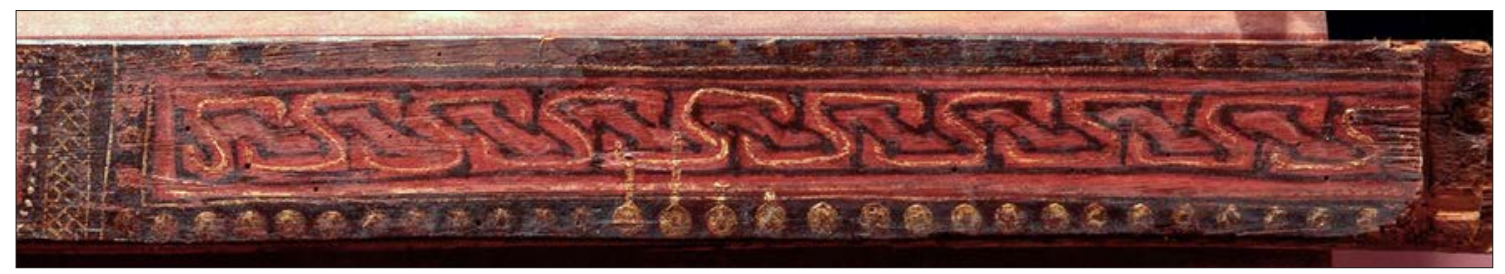

Figura 16. Detalle de la lacería presente en las vigas 2, 5 y 12.

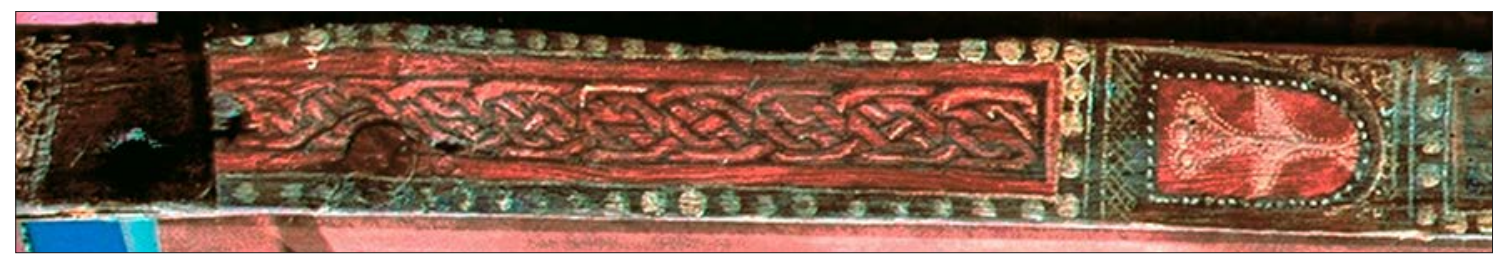

Figura 17. Lacería compleja; detalle de la viga 8. 
Vemos en otros casos una sencilla trenza (viga no 7), que se encuentra también sobre fondo negro en las vigas nos 1 y 7 (Fig. 18). Esta cenefa se repite en muchas piezas de época califal halladas por toda la Península: es similar a la que se dibujó sobre un plato de cerámica califal verde y manganeso hallado en la desaparecida madinat Ilbirra (Granada) (MARTíNEZ CAVIRÓ, 1991: f. 20, p. 43) o en una vasija de cuerda seca del museo de Jerez de la Frontera (siglos XII-XIII) (GONZÁLEZ, AGUILAR, BARRIONUEVO, 2015: f. 12A p. 62)

Hay dos vigas (nos 11 y 13) que repiten varias veces unas cenefas alejadas del modelo de lacerías de tradición clásica (que pervive en lo árabe) visto hasta ahora y que más bien recuerdan adornos renacentistas o las figuras vegetales que decoran la techumbre gótica de la iglesia de la Sangre (Llíria, Valencia), de principios del siglo XIV (CIVERA, 1989). La viga no 13 ha conservado la imagen a la que nos referimos con bastante nitidez (Fig. 19).

Una forma cuadrilobulada también conocida como nudo de Salomón, dibujada con líneas blancas, amarillas y negras sobre fondo rojo, ocupa el espacio vacío inferior a los lados de algunos de los escudos heráldicos de las caras vistas laterales (vigas nos 1, 10 y
13) (ver supra Fig. 12). Hay una figura cuadrilobulada idéntica, aunque con otros colores (generada a partir de líneas rojas y negras sobre fondo blanco), en los fragmentos de la cubierta mudéjar de la iglesia de San Martín de Teruel; estructura de madera que se fecha por la técnica de su pintura a mediados del siglo XIV (HERNANDO, 2007: foto 5, p.765 y 14, p. 768).

Pequeños trazos curvos que se incluyen como relleno son un motivo que se aprecia en bastantes recuadros con escudos (ver Figs. $1,2,8,12)$. A pesar de su simpleza y origen espontáneo, tienen las mismas características que los usados en la cerámica esgrafiada y la de reflejo metálico nazarí, que como se sabe imitan obras de la metalistería oriental selyuquí.

\section{LA DECORACIÓN HERÁLDICA}

En cuanto a los escudos que se ven en las vigas del MDB, existe un estudio de Leticia Darna que los describe, trata de asociarlos a familias catalanas y aborda su interpretación heráldica. Es un trabajo inédito al que hemos tenido acceso gracias a la amabilidad del MDB, que nos ha proporcionado una copia.

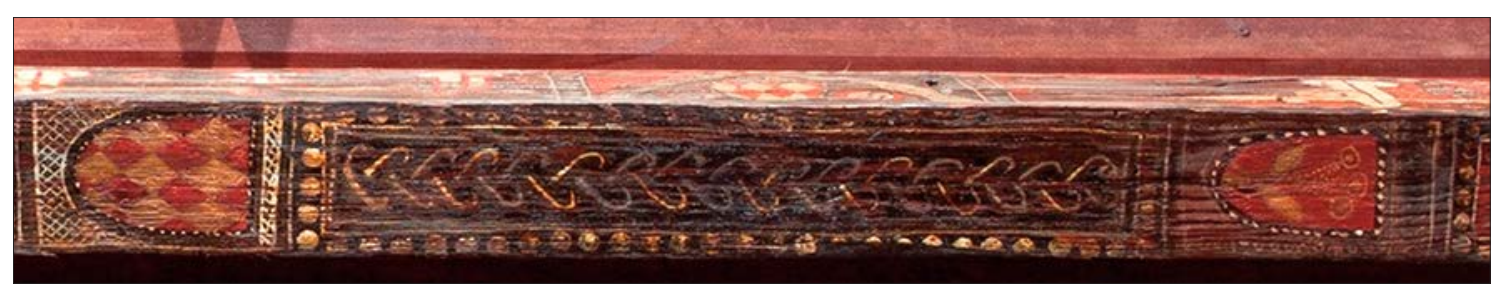

Figura 18. Detalle de lacería formando corazones presente en las vigas 1 y 7.

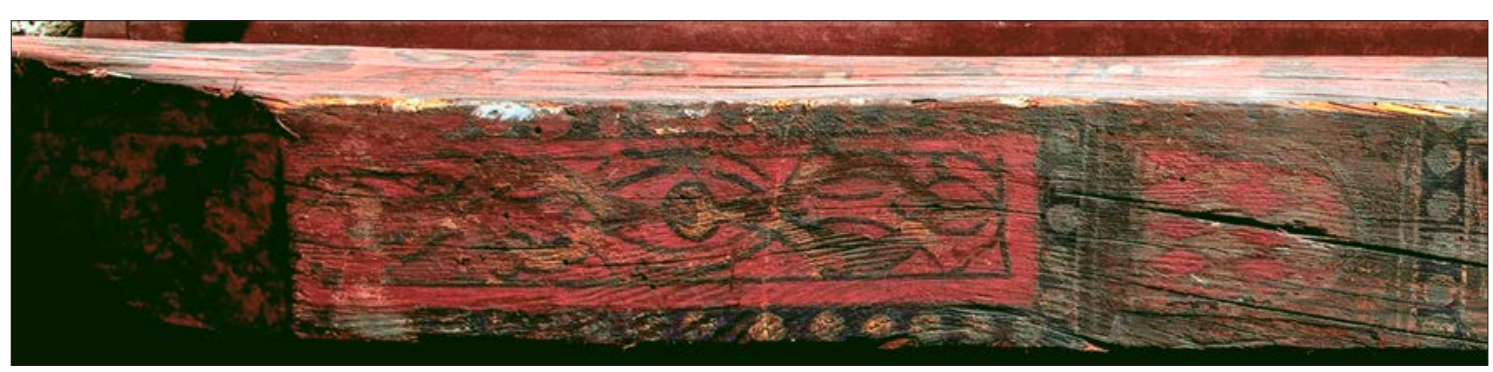

Figura 19. Detalle de la decoración de la viga 13. 
Destaca esta autora que hay escudos que aparecen una sola vez, mientras que otros se repiten en varias ocasiones (alguno incluso más de 10 veces). Ha intentado emparejarlos con los apellidos catalanes, aun cuando hace notar que en origen, en la época en que se pintaron las vigas (que data a mediados o finales del siglo XIV), un mismo blasón podía corresponder a diversas familias. No le ha sido posible relacionar los escudos presentes en las vigas con los de los linajes de los caballeros que acompañaron a Jaime I en la conquista de Mallorca, ya que señala que faltan algunos de los más importantes. Tampoco ha obtenido resultados positivos al confrontar los escudos presentes en las vigas con los de los canónigos de la Catedral de Barcelona en época de Pons de Gualba, obispo de Barcelona entre 1303 y 1334 (DARNA, 1995: p. 3). Concluye afirmando su creencia de que "los emblemas representados en estas vigas tienen un sentido exclusivamente ornamental y decorativo" (DARNA, 1995: p. 2).

Es una costumbre desarrollada en la decoración de techumbres mudéjares combinar adornos florales, caligrafías árabes y armería nobiliaria y real, como se puede contemplar en multitud de conventos, iglesias o palacios en toda la Península Ibérica.

Como bien explica Álvaro Zamora, "la unión de motivos vegetales musulmanes y góticos surge como fecha más temprana en el mudéjar toledano de mediados del siglo XIV, para difundirse después por otras zonas, en tanto que en Aragón la gotización del mudéjar no parece anterior al reinado de Pedro IV, ni se generaliza antes de fines del siglo XIV" (ÁLVARO, 1982: p. 236).

En nuestras vigas los escudos aparecen con la forma francesa antigua, apuntada y reducidas sus piezas y figuras a lo esencial; un tipo característico del último tercio del XIV que se mantiene a lo largo del XV. Casi todos ellos llevan bordura sable punteada en blanco, como los dibujados en la techumbre de Castro (Huesca) de la segunda mitad del siglo XV (ÁLVARO, 1982: p. 239). Decoración con escudos pintados dentro de arcos lobulados se ven en el alfarje del claustro del monasterio de Santo Domingo de Silos (Burgos), también de fines del siglo XIV (TORRES BALBÁS, 1949: f. 399 p. 353), entre otros muchos ejemplos que se podrían citar.

\section{HIPÓTESIS SOBRE LA REUTILIZACIÓN DE LAS VIGAS}

En general cuando las cubiertas de madera se decoran para ser vistas, quedan sin pintar las zonas ocultas, las que se empotran en la pared o reposan sobre otros elementos de sustentación. Normalmente la decoración se basa en una composición que tiene simetría y coherencia: el espacio se divide en porciones de dimensiones similares, cuyos colores alternan o tienen continuidad; el principio y el final de las vigas suponen el principio y el final de los motivos empleados.

Si las maderas del MDB se hubieran preparado y pintado para cubrir el espacio en que se encontraron, su decoración respondería a dichas características. Por el contrario, vemos que la caligrafía y las cenefas ornamentales aparecen cortadas abruptamente en un extremo o en ambos y ninguna de ellas se conserva en su integridad primera.

Hay que hacer notar también un hecho llamativo y anómalo: la disimetría en el reparto de los espacios y de los colores entre las caras laterales y los papos, hecho que no se observa en ninguna de las techumbres que conocemos. El efecto visual del conjunto resulta abigarrado y desordenado.

Esto lleva a suponer que las maderas decoradas del MDB eran en origen más largas y se cortaron después para adaptarlas al espacio en la Sala de la Trinitat. Así lo prueba el hecho de que siete de ellas muestren señales de encastre y sujeción en los extremos que tienen la decoración mutilada. Aunque podría responder a otras causas, todo esto hace pensar que habían estado en la techumbre de otro lugary se reciclaron. ¿Estaban en la propia Barcelona o vinieron de una procedencia más lejana? No podemos dar respuesta a esta pregunta. 
Es un hecho que a lo largo de la historia las cubiertas de madera se han desmontado y vuelto a montar, se han trasladado y se han adaptado de unos espacios a otros, cambiando así de edificio e incluso de ciudad. Recordemos las ya citadas techumbres de Xàtiva trasladadas a Barcelona por Martín I, - el alfarje de la antigua Casa de la Ciudad de Valencia, instalado hoy en la Lonja, en la Sala del Consulado de Mar (MARTínEZ, 2012).

Cuando en el año 1669 las naves de la iglesia de San Millán de Segovia se cubrieron con bóvedas barrocas y se desmontaron los alfarjes, sus vigas se trocearon en dos o tres partes y se reaprovecharon para una nueva armadura de cubierta inclinada (HERRERA, CABAÑERO, 1999: 212).

Este es uno de los muchos ejemplos que se podrían aducir que muestra, además de la adaptación, el paso de las maderas de una techumbre plana a otra inclinada. Algo así pudo suceder con las vigas que nos ocupan, pues en el momento en que se desmontaron de la Sala de la Trinitat formaban parte de una techumbre a dos aguas, como puede observarse en el proyecto de restauración y ampliación del Archivo Diocesano redactado por el arquitecto Joan Bassegoda Nonell entre 1980 y 1982 (Fig. 20) y en las fotos que se conservan de las obras (Fig. 21).

Hasta aquí hemos podido comprobar que la disposición y trazado de la caligrafía árabe, el estilo de la decoración vegetal y de las composiciones en las que se inscriben los escudos llevan a un período cronológico que comienza con lo almohade en la primera mitad del siglo XIII y termina a mediados del siglo XIV. Sin embargo, el arco temporal se puede reducir teniendo en cuenta las coincidencias generales que apuntan hacia el final del período, es decir cerca de 1350.

La estancia de la que proceden las vigas está en el último piso de la denominada "ala de la capella", cuya fundación se data entre

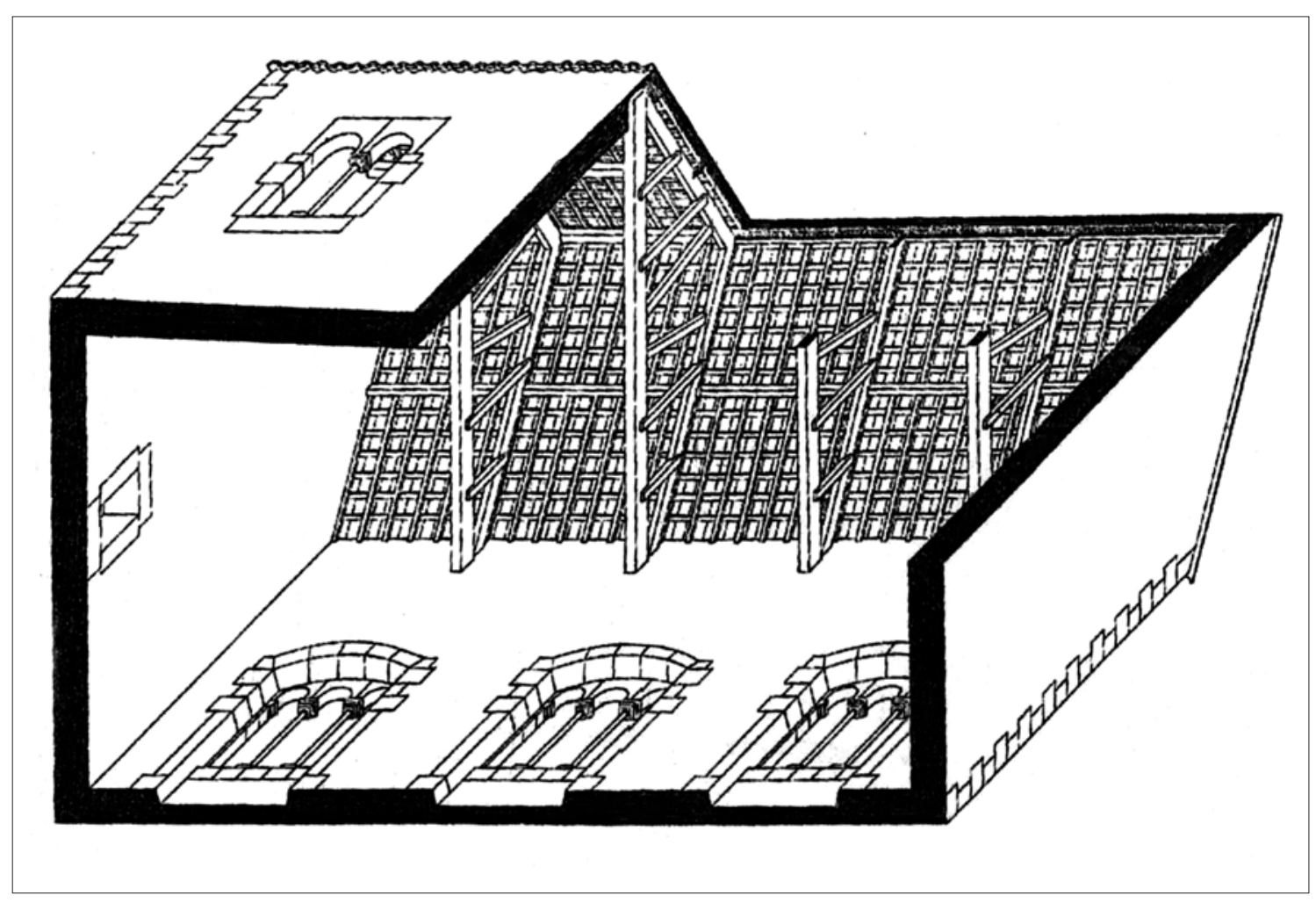

Figura 20. Joan Bassegoda Nonell: Proyecto de restauración y ampliación del Archivo Diocesano. Axonometria Sala de la Trinitat (1982). (Archivo Diocesano de Barcelona. Palau Episcopal. Papers solts.

Cortesía del MDB) 


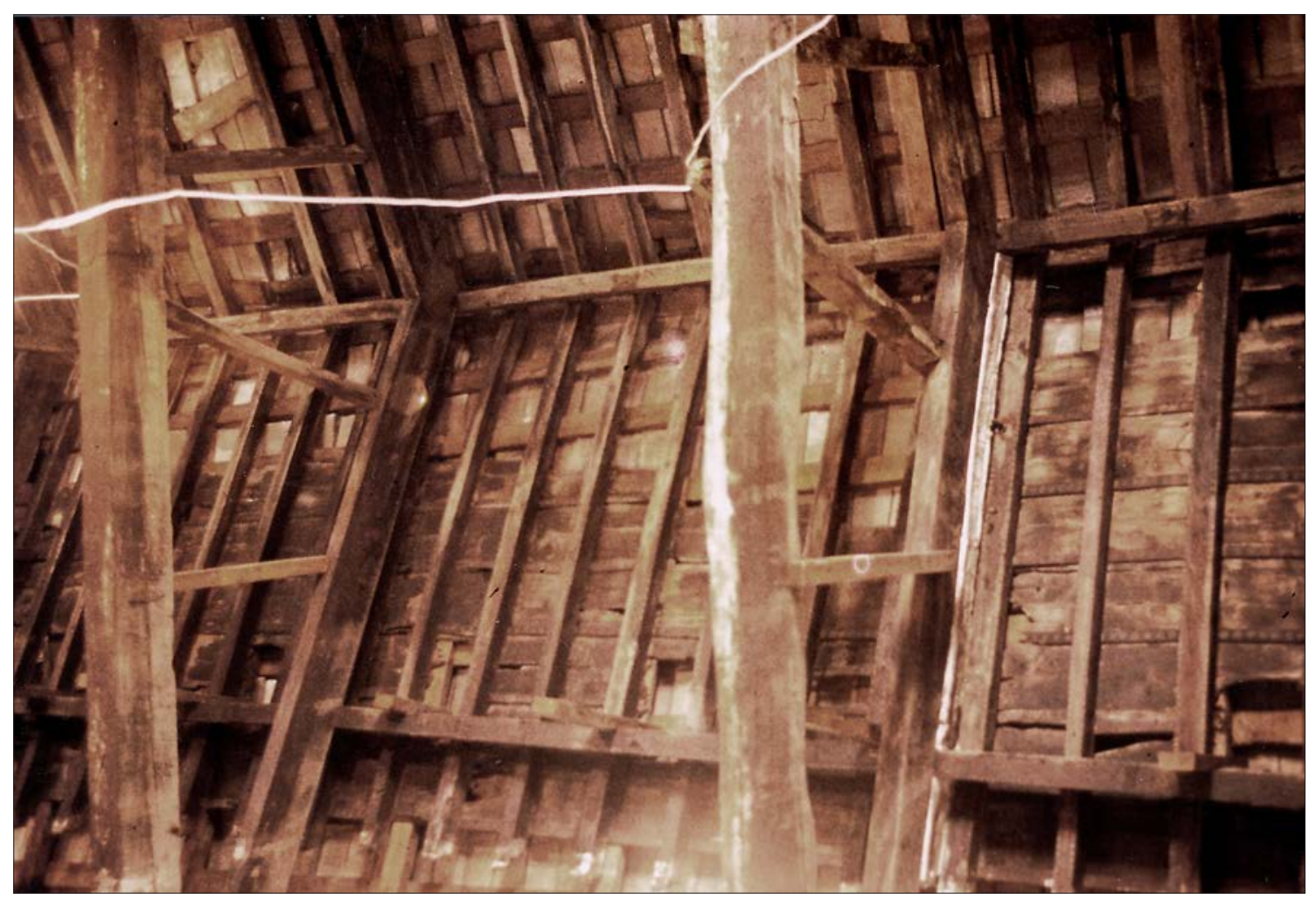

Figura 21. Fotografía de la techumbre de la Sala de la Trinitat durante las obras de restauración (Cortesía del MDB).

1253 y 1257 (MÀRIA, MINGUELL, 2009-2010: pp. 67-68). Tal vez debido al conocimiento de esta cronología, y a algún malentendido, estos autores relacionan las vigas con la conquista de Mallorca, lugar del que las hacen proceder, pues afirman que "I'antiga coberta d'aquesta estança conservava elements originals del segle XIII, en particular les bigues amb epigrafia àrab i heràldica feudal catalana, provinents de la conquesta de Mallorca" (MÀRIA, MINGUELL, 2009-2010: p. 85).

Como hemos visto, todos los elementos de la decoración, y en especial la presencia de escudos heráldicos, llevan a un entorno cultural cristiano y una datación más moderna, con paralelos además en toda una serie de cubiertas de madera catalanas y más concretamente barcelonesas que presentan también versiones degradadas del motivo epigráfico árabe al-mulk li-llāh (MASPOCH, 2013b).

Se observará la discrepancia de un siglo entre la cronología que se atribuye a la construcción inicial de las habitaciones en que se hallaron y la fecha que proponemos para las vigas. Y es que falta demostrar que la techumbre que nos ocupa proceda originalmente de ese edificio, que fuera contemporánea de la planta baja de ese ala, y que sea la original, sin que se haya cambiado nunca hasta 1980 y sin que jamás se hicieran reformas o reparaciones en la cubierta de esa zona del palacio.

\section{BIBLIOGRAFÍA}

ADROER I TASIS, Anna M. (1998): "Enteixinats de Xàtiva al Palau Major de Barcelona”, Analecta Sacra Tarraconensia, 71, pp.43-52.

ÁLVARO ZAMORA, Ma. Isabel (1982): "La techumbre de Castro (Huesca)", Actas II Simposio Internacional de mudejarismo: Arte. 1981. Teruel, Instituto de Estudios Turolenses, pp. 227-240.

ANGULO, Diego (1984): Historia del arte. Madrid, Raycar

BEUTER, P. A. $(1538$ = 1971): Primera part de la Història de València, edició facsímil amb una nota preliminar de Joan Fuster. València, Imprempta Soler.

CIVERA MARQUINO, Amadeo (1989): Techumbre góticomudéjar en la iglesia de Santa María o de la Sangre en Llíria. Llíria, Ayuntamiento de Llíria. 
Corpus epigráfico de la Alhambra. Palacio de Comares. (2008). Libro CD y DVD-Rom. Granada, Patronato de la Alhambra y Generalife; Escuela de Estudios Árabes (CSIC).

DARNA GALOBART, Leticia (1995): “Consideración heráldica de unas vigas procedentes del Palacio Episcopal de Barcelona, expuestas actualmente en el edificio de la Pía Almoina". Trabajo inédito.

GONZÁLEZ MARTÍ, Manuel (1944): Cerámica del Levante español. Siglos medievales. Loza. Barcelona, Labor.

GONZÁLEZ, Rosalía; AGUILAR, Laureano; BARRIONUEVO, Francisco J. (2015): Los colores del poder. La cerámica en "verde y manganeso" de Jerez de la Frontera (Cádiz). Cádiz, Presea.

HERNANDO SEBASTIÁN, Pedro Luis (2007): "Aportación al estudio de las cubiertas de madera mudéjares. Los fragmentos de una estructura de madera mudéjar de la iglesia de San Martín de Teruel", Actas X Simposio Internacional de Mudejarismo. Teruel, 14-16 septiembre 2005. Teruel, Centro de Estudios Mudéjares. Instituto de Estudios Turolenses, pp. 759-772.

HERRERA ONTAÑÓN, Valero; CABAÑERO SUBIZA, Bernabé (1999): "La techumbre mudéjar de la iglesia de San Millán de Segovia. Estudio de una obra maestra del arte taifal digna de ser recuperada", Artigrama, 14, pp. 207-240.

KAGAN, Richard L. (1986): Ciudades del Siglo de Oro. Las vistas españolas de Anton Van den Wyngaerde. Madrid, El Viso.

LÓPEZ GUZMÁN, Rafael (coord.) (1995): La arquitectura del islam occidental. Barcelona, Lunwerg - El Legado andalusí.

MAÑAS, Fabián (1982): "Reconstrucción del palacio del Condestable Miguel Lucas de Iranzo (Jaén)", Actas II Simposio Internacional de mudejarismo: Arte. 1981. Teruel, Instituto de Estudios Turolenses, pp. 173-178.

MÀRIA I SERRANO, Magda; MINGUELL I FONT, Joan Claudi (2009-2010): "El Palau Episcopal de Barcelona. Cronologia arquitectònica d'un edifici de vint segles d'història", Locvs Amoenvs, 10, pp. 63-86.

MARTÍNEZ CAVIRÓ, Balbina (1991): Cerámica hispanomusulmana. Andalusí. Mudéjar. Madrid, El Viso.

MARTíNEZ VALENZUELA, María Montserrat (2012): El Alfarje de la antigua Casa de la Ciudad. Técnico, histórico y de conservación en su nueva ubicación, la Lonja de Valencia. Valencia, Centro de Estrategias y Desarrollo de Valencia Servicio de publicaciones del Ayuntamiento de Valencia.

MASPOCH, Mònica (2013): "Aproximació historiogràfica dels embigats policromats medievals en arquitectura domèstica catalana. El cas de Barcelona", Quaderns del Museu Episcopal de Vic, 6, pp. 59-70.

MASPOCH, Mònica (2013b): Els embigats medievals en l'arquitectura domèstica barcelonina: tipologies estructurals i programes pictòrics. Tesis Doctoral inédita. Universidad de Barcelona. Lectura 20.12. 2013.
MATEOS PARAMIO, Alfredo (com.) (2010): Memoria de los moriscos. Escritos y relatos de una diáspora cultural. Madrid, Sociedad Estatal de Conmemoraciones Culturales.

NAVARRO PALAZÓN, Julio (1995): “Un palacio protonazarí en la Murcia del siglo XIII: Al-Qașr al-Șagīr", NAVARRO PALAZÓN, Julio (coord.) Casas y palacios de al-Andalus. Siglos XII y XIII. Barcelona - Granada, Lunwerg - El Legado Andalusí, pp. 177-205.

NAVARRO PALAZÓN, Julio; JIMÉNEZ CASTILLO, Pedro (1995): "El Castillejo de Monteagudo: Qașr Ibn Sa'd", NAVARRO PALAZÓN, Julio (coord.) Casas y palacios de al-Andalus. Siglos XII y XIII. Barcelona - Granada, Lunwerg - El Legado Andalusí. pp. 63-103.

NAVARRO PALAZÓN, Julio; JIMÉNEZ CASTILLO, Pedro (1995b): "La decoración protonazarí en la arquitectura doméstica: La Casa de Onda”, NAVARRO PALAZÓN, Julio (coord.) Casas y palacios de al-Andalus. Siglos XII y XIII. Barcelona - Granada, Lunwerg - El Legado Andalusí, pp. 207-223.

NUERE, Enrique (1989): La Carpintería de armar española. Madrid, Ministerio de Cultura.

OCAÑA JIMÉNEZ, Manuel (1970): El cúfico hispano y su evolución. Madrid, IHAC.

OCAÑA JIMÉNEZ, Manuel (1990): "Panorámica sobre el arte almohade en España", Cuadernos de la Alhambra, 26, pp. 91-111.

PAVÓN, Basilio (1976): El arte hispanomusulmán en su decoración geométrica. Madrid, Instituto de Cooperación con el Mundo Árabe.

PAVÓN MALDONADO, Basilio (1981): El arte hispanomusulmán en su decoración floral. Madrid Instituto de Cooperación con el Mundo Árabe.

PUERTA VÍLCHEZ, José Miguel (2010): Leer la Alhambra. Guía visual del monumento a través de sus inscripciones. Granada, Patronato de la Alhambra.

RUBIÓ I LLUCH, Antoni (1921): Documents per l'Història de la cultura catalana mig-eval. Barcelona, Institut d'Estudis Catalans.

SALEM, 'Abd al-'Azìz (1978): "La puerta del Perdón en la gran mezquita de la alcazaba almohade de Sevilla", Al-Andalus, 43, pp. 201-207.

TORRES BALBÁS, Leopoldo (1949): Arte almohade. Arte nazarí. Arte mudéjar. (Ars Hispaniae IV). Madrid, PlusUltra.

VALLEJO TRIANO, Antonio (2010): La ciudad califal de Madinat al-Zahrā.' Arqueología de su arquitectura. Jaén, Almuzara. 